\title{
Effect of Pre-Hatching Thermal Conditioning and Post-Hatch Vitamin C Addition on Productive Performance and Some Blood Parameters of Broiler Chicks. Tag El-Din, H. T. ${ }^{1}$; I. El-Wardany ${ }^{2}$ and Sara H. M. Hasab ${ }^{1}$. \\ ${ }^{1}$ Dept of Poult. production, Fac.of Agric. Damieta Univ. \\ ${ }^{2}$ Dept of Poult. production, Fac.of Agric. Ain shams Univ.
}

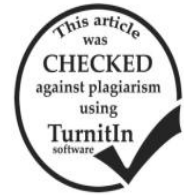

\begin{abstract}
The present study was conducted to evaluate the rale of thermal conditioning (TC) of broiler eggs during incubation period, and vitamin C (VC) supplementation to drinking water of hatched chicks on their performance and some blood parameters. A total of 300 eggs were assigned randomly to three experimental groups: control and two thermal conditioning groups (TC-7 and TC-14) which were exposed to $39.5 \pm 0.5^{\circ} \mathrm{C}$ for $4 \mathrm{~h}$ at the $7^{\text {th }}$ or $14^{\text {th }}$ day of incubation respectively. After hatching, each group was subdivided into two subgroups a control and VC-supplemented one. Vitamin C was supplied at a level of $1 \mathrm{~g} /$ liter of drinking water. The experimental was extended for 5 weeks. Growth performance and blood protein were measured. Results showed that live body weight (LBW) was significantly increased at the first week of age, but no differences in LBW were detected at the other ages. However there were an insignificant increase in the final LBW chicks of TC-7 and TC- 14 . Administration of VC significantly increased LBW of chicks at 4 and 5 weeks of age compared with the control group. No significant effect of TC on Body Weight Gain (BWG) of chicks at different ages, however, VC addition has a significant effect on BWG at the periods from 3-5 weeks of age and for the whole period. Feed intake was significantly affected by TC treatments, where chicks from TC-7group showed an increase than the other groups. Vitamin C addition significantly reduced feed intake of broiler chicks at 4-5 weeks of age and for the whole period. Feed conversion ratio (FCR) was not significantly affected by either TC or VC addition during the the whole period, but there were significant improvement in FCR for TC-7 chick's group at the period from 1-2 wk and for VC-treated chicks at 3-4 weeks of age. There were non significant effects of TC treatment on blood plasma protein fractions, however VC addition significantly increased plasma total protein level. It is concluded that thermal manipulation of broiler eggs at different period of incubation and vitamin $\mathrm{C}$ addition for hatched chicks could be used as a practical approach to alleviate the negative impact of heat stress on broiler chicks performance.
\end{abstract}

\section{INTRODUCTION}

Manipulation of incubation temperature was known to have an influence on both embryonic development and the hatching process. However, the magnitude and direction of this influence is largely dependent on the period during incubation and the frequency, duration, and amplitude of temperature manipulation Willemsen et al., (2011). Piestun et al.(2009), found significant reduction in embryonic growth when subjecting embryos to continuous thermal $\left(39.5^{\circ} \mathrm{C}\right)$ manipulation from ED 7 to ED 16. Several studies found decreased performance in chickens that were exposed to higher than optimal air temperature Donkoh,( 1989); Yahav et al., (1995); Geraert et al., (1996) and Yahav and Plavnik, (1999). On the other hand, Thompson et al. (1976)., Lay and Wilson (2002)., and Yalcin and Siegel (2003) found that increasing the incubation temperature had no effect on hatching rate or body weight $(\mathrm{BW})$. The main consequence of heat stress is the reduction in feed intake as a trial from the bird to reduce the metabolic heat production May and Lott, (1992). This will cause poor growth, reduced feed conversion ratio and enhanced fat deposition due to hypothyroid activity Geraert et al., (1996) and Mashaly,(2004). To alleviate the negative impact of heat stress many practical approaches have been used to facilitate theromotolerance of birds. These methods include pre or post thermal conditioning of birds Yahav and Plavnik, (1999); Abd El-Azim,( 1991), use of some electrolytes and vitamins Teeter, et al., (1985); Sahin, et al., (2003 a,b,c ). The interaction effect of prehatching heat conditioning and post hatch vitamin $\mathrm{C}$ addition on growth performance of broiler chicks reared under hot summer environment was not extensively studied. Therefore, the main objective of the present study was to evaluate the influence of thermal conditioning of broiler eggs during incubation period and post hatch vitamin C supplementation to drinking water on growth performance of broiler chicks.

\section{MATERIALS AND METHODS}

The present study was conducted at the Poultry Physiology Laboratory, Department of poultry production, Faculty of Agriculture, Ain shams University, during summer months (May - June, 2016 ) of Egypt .

Three hundred eggs were randomly divided into three groups of 100 eggs each. The first group was kept as a control (C) group, the second was exposed to heat stress $\left(39.5 \pm 0.5^{\circ} \mathrm{C}\right)$ for 4 hours at the 7 th day of incubation (TC7 ), while the third group was exposed to the same temperature at the 14th day of incubation (TC-14). All eggs were incubated in a commercial incubator at $37.5^{\circ} \mathrm{C}$ and $55 \% \mathrm{RH}$ as recommended by Bruzual et al.(2000). At the 18th day of incubation, eggs from each of the three treatments were transferred from turning trays to hatcher baskets. After hatch, a total of 90 healthy chicks representing the three groups (30 chick/treatment) were chosen, weighed and transferred to the brooding pens. Upon arrival, the chicks were randomly divided into two subgroups of 15 chicks in three replicates 5 chicks each, where the first subgroup was kept as control and the other one was supplied with vitamin $\mathrm{c}(\mathrm{VC})$ at a level of $1 \mathrm{~g}$ /Liter of drinking water from the first day till the end of the experiment period ( 35 days of age).

Chicks of all treatments were reared under similar hygienic and environmental conditions under the prevailing hot climates of summer season environment. The brooding temperature was $33^{\circ} \mathrm{C}$ during the first weeks, and then reduced $2^{\circ} \mathrm{C}$ until it reached the room temperature (indoor temperature of $30-35^{\circ} \mathrm{C}$ ) for the whole period.

Chicks were vaccinated against Newcastle virus (NDV); Avian Flu and IBDV (Gumboro) diseases at the recommended times. All chicks were exposed to $23 \mathrm{~h}: 1 \mathrm{~h}$ ( Light: Dark) schedule during the experiment period and 
fed the experimental diets (Starter, Grower and Finisher) that formulated according NRC (1994) to satisfy the recommended requirements of Avian chicks strain . Composition and calculated analysis of the experimental diets are show in Table (1).

Table 1. Composition and calculated analysis of the experimental diets

\begin{tabular}{lccc}
\hline Ingredient (\%) & Starter & Grower & Finisher \\
\hline Yellow corn & 55.600 & 62.750 & 65.0 \\
Soybean meal (44\%) & 28.700 & 21.450 & 23.0 \\
Corn gluten meal (60\%) & 8.950 & 8.950 & --- \\
Di-ca phosphate & 2.185 & 2.080 & 2.0 \\
Vegetable oil & 2.300 & 2.500 & --- \\
Sodium Bicarbonate & 0.20 & 0.20 & 0.20 \\
Limestone & 1.035 & 0.920 & 1.240 \\
Methionine & 0.175 & 1.180 & 0.160 \\
Lysine & 0.295 & 0.420 & 0.140 \\
Premix & 0.300 & 0.300 & 0.300 \\
Wheat bran & --- & -- & 45.1 \\
Salt & 0.3 & 0.3 & 0.3 \\
Total & 100 & 100 & 100 \\
\hline \multicolumn{3}{l}{ Calculated analysis** } & \\
Crude protein \% & 23.0 & 20.51 & 16.08 \\
ME Kcal/Kg & 3052 & 3152 & 2138 \\
Crude fiber \% & 3.5 & 3.13 & 6.75 \\
Methionine+cysteine & 0.97 & 0.93 & 0.72 \\
Lysine \% & 1.3 & 1.2 & 0.89 \\
Calcium \% & 1.03 & 0.94 & 1.05 \\
Av.Phosphorus & 0.5 & 0.47 & 0.52 \\
\hline Vitams and & &
\end{tabular}

Vitamins and mineral premix per Kg of diet: a Mineral-vitamin premix provided the following per kilogram of diet contains $=$ A,12000 I.U., E, 10 mg., B1, 2mg., B2,5mg., B6, 4mg ., B12, 10 mg., Niacin, $25 \mathrm{mg}$.,Pantothenic acid, $10 \mathrm{mg}$., Biotin, $50 \mathrm{mg}$., Folic acid, 1000 mg., and Coline chloride, 255 mg. Selenium $300 \mathrm{mg}$., Copper, $10 \mathrm{mg}$. Iodine, $1.0 \mathrm{mg} ., \mathrm{K}, 2.0 \mathrm{mg}$., Iron, $33 \mathrm{mg}$., Manganese, 60 mg., and, 60mg Zinc. ** Acording to NRC (1994).

Measurements:

a- Growth performance:

Chicks were individually weighed at 1,21 and 35 days of age. Body weight (BW), body weight gain (BWG), and feed intake (FI) of broilers were recorded.
Feed conversion ratio (FCR) was calculated by dividing FI by body weight gain (BWG) at different intervals.

\section{b- Blood sampling and analysis:}

A total of 18 blood samples were collected at 35 days of age into heparinized tubes (3 samples/treatment), immediately centrifuged (4000 r.p.m.) for $15 \mathrm{~min}$ using laboratory centrifuge (SMIC, YJ03, Shanghahi, China) and plasma samples were decanted into Ependorfer tubes, then stoppered tightly and stored at $-20^{\circ} \mathrm{C}$ until biochemical analyses were done. Plasma total protein (TP) and albumin (Alb) were spectrophoto meterically determined by using available Commercial kits as described by the Manufacturer Procedures (spectrum, Diagnostics, Egypt. Co. for Biotechnology, S. A. E). Globulin was estimated by subtracting the values of Alb from the corresponding values of TP per sample.

Data were subjected to two-way analysis of variance by using the General Linear models procedure (GLM) of the Statistical Analysis System (SAS,1994), according to the following model:

\section{Where:}

$$
Y \mathbf{i j k}=\mu+T \mathbf{T}+\mathbf{V j}+\mathbf{T V i j}
$$

Yijk = an observation.

$\mu=$ overall mean.

$\mathrm{Tj}=\mathrm{a}$ fixed effect of thermal treatment. $(\mathrm{j}=1,2$ and 3$)$

$\mathrm{Vi}=\mathrm{a}$ fixed effect of vitamin $\mathrm{C}$ treatment. ( $\mathrm{i}=1$ and 2$)$

$\mathrm{TVij}=$ the interaction of $\mathrm{T}$ and $\mathrm{V}$.

eijk $=$ experimental error.

Differences among treatment means were detected by using Ducan's multiple range test (Duncan,1955).

\section{RESULTS AND DISCUSSION}

Live body weight (LBW)

Live body weight (LBW) of broiler chicks as influenced by TC during incubation is presented in Table -2 .

Table 2. Effect of thermal conditioning during incubation period on live body weight of broiler chicks.

\begin{tabular}{|c|c|c|c|c|c|c|}
\hline 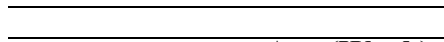 & & ve Body & & & & \\
\hline Age (Weak) & $\mathbf{0}$ & 1 & 2 & 3 & 4 & 5 \\
\hline Thermal Conditioning (TC) & & & & & & \\
\hline Control "C1" & 46.13 & $214.20 \mathrm{~b}$ & 468.17 & 923.20 & 1431.20 & 1722.13 \\
\hline TC-7 & 46.10 & $226.23 \mathrm{a}$ & 472.47 & 970.27 & 1434.57 & 1762.83 \\
\hline TC-14 & 45.90 & $209.87 b$ & 479.73 & 927.50 & 1456.60 & 1741.13 \\
\hline SEM & 0.56 & 3.20 & 7.79 & 26.47 & 23.14 & 49.62 \\
\hline Significance & NS & $*$ & NS & NS & NS & NS \\
\hline Vitamin-C Effect (VC) & & & & & & \\
\hline Control "C" & 45.73 & 213.33 & 467.93 & 948.40 & $1383.16^{\mathrm{O}}$ & $1776.33^{\circ}$ \\
\hline $\mathrm{VC}$ & 46.36 & 220.20 & 478.98 & 932.24 & $1498.42^{\mathrm{a}}$ & $1832.82^{\mathrm{a}}$ \\
\hline SEM & 0.46 & 2.61 & 6.36 & 21.62 & 18.89 & 40.53 \\
\hline Significance & NS & NS & NS & NS & $*$ & $*$ \\
\hline $\mathrm{TC} \times \mathrm{VC}$ Interaction & & & & & & \\
\hline $\mathrm{C} 1 \times \mathrm{C}$ & 45.53 & 213.73 & 459.87 & 914.93 & 1391.33 & 1718.40 \\
\hline $\mathrm{C} 1 \times \mathrm{VC}$ & 46.73 & 214.67 & 476.47 & 931.47 & 1471.07 & 1768.13 \\
\hline $\mathrm{TC} 7 \times \mathrm{C}$ & 45.33 & 220.73 & 457.47 & 978.13 & 1372.13 & 1727.73 \\
\hline $\mathrm{TC} 7 \times \mathrm{VC}$ & 46.87 & 231.73 & 487.47 & 962.40 & 1497.00 & 1780.13 \\
\hline $\mathrm{TC} 14 \times \mathrm{C}$ & 46.33 & 205.53 & 486.47 & 952.13 & 1386.00 & 1752.87 \\
\hline $\mathrm{TC} 14 \times \mathrm{VC}$ & 45.47 & 214.20 & 473.00 & 902.87 & 1527.20 & 1791.20 \\
\hline SEM & 0.80 & 4.53 & 11.02 & 37.44 & 32.72 & 70.20 \\
\hline Significance & NS & NS & NS & NS & $\mathrm{NS}$ & $\mathrm{NS}$ \\
\hline
\end{tabular}

a, $b$ and $c$ Mean within columns with different superscripts are significantly different $(P<0.05)$. NS $=$ not significant, $*=$ significant at $5 \%$ level, $* *=$ significant at $1.0 \%$ level.

Data revealed that LBW of broiler at the first week of age was significantly $(\mathrm{P} \leq 0.05)$ higher for chicks that hatched from eggs which exposed to TC at the 7th day of incubation compared by those of the control and TC-14 treatment. However, TC did not exert significant effects on LBW of chicks during the other growth periods. Regardless, the effect of TC on LBW, our results showed that Vitimin C (VC) administration in drinking water had significant 
influence on LBW of chicks at 4 and 5 weeks of age, furthermore the $\mathrm{TC} \times \mathrm{VC}$ interaction effect, the present study showed insignificant influence of both variables on LBW. It appears that TC during incubation period did affect the posthatch growth performance of broiler chicks during the most period of growth (i.e.2-5 weeks of age ). This was also confimed by the results obtained by Abd El-Azim (1991) and Yalcin and Siegel (2003) who reported that the change in LBW of broiler chicks as a result of prehatch temperature exposuse have disappeared with age.That vitamin $\mathrm{C}$ addition to drinking water causes an improvement in LBW of chicks at 4 and 5 weeks of age, may be due to the beneficial effect of Vit.C on alleviating the negative impact of summer heat stress imposed to chicks on feed intake and hence the increased LBW was achieved . It possible ,also ,that VC can affect both corticosterone and thyroid hormones secretion and / or releasing rates as an adaptive response of broiler chicks , especially for those exposed to epigenetic thermal adaptation during incubation period .

Body Weight Gain:

Body Weight Gain (BWG) of broiler chicks as influenced by TC during incubation and post hatch VC administration is presented in Table -3 .

Data revealed that BWG of broiler chicks at the period from 0 to 1 weak of age was significantly $(\mathrm{P} \leq 0.05)$ higher for chicks that hatched from eggs which exposed to TC at the 7th day of incubation compared by those of the control and TC-14 treatment. However, TC did not exert significant effects on BWG of chicks during the other weaks. Regardless, the effect of TC on BWG, our results showed that Vitimin C (VC) administration in drinking water had significant influence on BWG of chicks at the period from 3 to 4,4 to 5 and 0 to 5 weeks of age. But the period from 4 to 5 and 0 to 5 weeks of age was significantly $(\mathrm{P} \leq 0.05)$ higher than for control. Concerning the $\mathrm{TC} \times \mathrm{VC}$ interaction effect, the current study showed insignificant influence of both variables on BWG. It is apparent from these result that the more obvious unfluence of treatment on BWG was clear for vitamin C treatments after post hatching, especially during the period. This effect is related to the thermal challenge during from 3 to 5 weeks of age and for the thermal challenge during the growing period, with it severity being accused for the control group, and hence VC alleviated this negative effect.this result is in close agreement with those reported by kutlu and Forbes(1993a,b), Mckee and Hassison (1995); Sahin et al. (2003b) and Imik et al.(2013) who found that VC caused an increase in CRF from hypothalamic centers, and hence stimulates ACTH secretion, consequently elevated corticosterone level in blood. This hormone was known to enhance nutrients metabolism which may explain the significant increase in body weight gain of chicks at the end of the experiment. This was confirmed by the results of Yahav (2002) who stated that thermoregulation in birds is controlled by changes in the temperature of thermoreceptors in the central nervous system, i.e., changes in the " set point " to cope with extreme environmental conditions along with the maturation of Hypothalamus - Pituitary - Adrenal (HPA) axis , which support our results .

Table 3. Effect of thermal conditioning during incubation period on Body Weight Gain of broiler chicks.

\begin{tabular}{|c|c|c|c|c|c|c|}
\hline \multicolumn{7}{|c|}{ Body Weight Gain } \\
\hline $\begin{array}{l}\text { Age (Weak) } \\
\text { Variable }\end{array}$ & 0-1 Wk & 1-2 WK & 2-3 WK & 3-4WK & 4-5 WK & 0-5 WK \\
\hline Thermal Conditioning (TC) & & & & & & \\
\hline Control "C1" & $168.07^{\circ}$ & 253.97 & 455.04 & 508 & 290.92 & 1676.10 \\
\hline TC-7 & $180.13^{\mathrm{a}}$ & 246.24 & 497.80 & 464.36 & 328.62 & 1716.73 \\
\hline TC-14 & $163.97^{\circ}$ & 269.86 & 447.77 & 529.10 & 284.53 & 1695.23 \\
\hline SEM & 3.16 & 7.75 & 26.41 & 23.06 & 49.62 & 61.44 \\
\hline Significance & & NS & NS & NS & $\mathrm{NS}$ & NS \\
\hline Vitamin-C Effect (VC) & & & & & & \\
\hline Control "C" & 167.60 & 254.6 & 480.47 & $434.76^{\mathrm{D}}$ & $393.20^{\mathrm{a}}$ & $1730.66^{\mathrm{D}}$ \\
\hline $\mathrm{VC}$ & 173.84 & 258.48 & 453.26 & $566.18^{\mathrm{a}}$ & $334.40^{\circ}$ & $1786.50^{\circ}$ \\
\hline SEM & 2.58 & 16.14 & 27.80 & 43.02 & 46.35 & 99.69 \\
\hline Significance & NS & NS & NS & T. & * & $*$ \\
\hline TC $\times$ VC Interaction & & & & & & \\
\hline $\mathrm{C} 1 \times \mathrm{C}$ & 168.2 & 246.14 & 455.06 & 476.4 & 327.07 & 1672.87 \\
\hline $\mathrm{C} 1 \times \mathrm{VC}$ & 167.94 & 26.18 & 455 & 539.6 & 297.06 & 1721.40 \\
\hline $\mathrm{TC} 7 \times \mathrm{C}$ & 175.4 & 236.74 & 520.66 & 394 & 355.60 & 1682.10 \\
\hline $\mathrm{TC} 7 \times \mathrm{VC}$ & 184.86 & 255.74 & 474.93 & 534.6 & 283.13 & 1733.23 \\
\hline $\mathrm{TC} 14 \times \mathrm{C}$ & 159.2 & 280.94 & 465.66 & 433.87 & 366.87 & 1706.54 \\
\hline $\mathrm{TC} 14 \times \mathrm{VC}$ & 168.73 & 258.8 & 429.87 & 624.33 & 264.04 & 1745.73 \\
\hline SEM & 10.21 & 13.01 & 27.98 & 30 & 26.7 & 99.69 \\
\hline Significance & NS & NS & NS & NS & NS & NS \\
\hline
\end{tabular}

a, b and c Mean within columns with different superscripts are significantly different $(P<0.05)$. NS $=$ not significant, * $=$ significant at $5 \%$ level, ** = significant at $1.0 \%$ level.

\section{Feed intake and Feed confertion ratio}

Feed intake(FI) of broiler chicks as influenced by TC during incubation period and $\mathrm{VC}$ addition to drinking water of hatched chicks is presented in Table -4 .

Data revealed that feed intake of broiler chicks at the priod from 2 to 3,3 to 4,4 to 5 weeks of age and for the whole period $(0-5 \mathrm{wk})$ was significantly $(\mathrm{P} \leq 0.05)$ higher for chicks that hatched from eggs which exposed to TC. The period from 3 to $4 \mathrm{wk}$ showed that was significantly at control and 14th day of incubation. Both the priod 2 to 3,4 to
5 and 0 to 5 weeks of age was significantly at 7 th day of incubation. However, TC did not exert significant effects on feed intake of chicks during the other growth period. Regardless, the effect of TC on feed intake, our results showed that Vitimin C (VC) administration in drinking water had significant influence on feed intake of chicks at the period 2 to 3 and 3 to 4 weeks of age. But (0) had significant influence on feed intake of chicks at the period 4 to 5 and 0 to 5 weeks of age. Higher $(\mathrm{P} \leq 0.05)$ feed intake compared by VC-treated chicks. Results showed also that the 
$\mathrm{TC} \times \mathrm{VC}$ interaction was significant where chicks from TC$7 \times \mathrm{VC}$ and control $(\mathrm{C} \times \mathrm{VC})$ groups had recorded the lowest feed intake during the whole experiment period. Concering the effect of different treatment on feed confertion ratio (FCR). The present results showed that TC etheir at the 7th or 14th of incubation period did not have significant effects on FCR at different ages (Table-5), except for the period from 1 to 2 weeks of age. During this period, FCR was significantly better for the control and TC-7 chick groups compored by those from TC-14 chicks group. Similarly, vitamin $\mathrm{C}$ addition to drinking water, regardless of TCtreatment, had insignificant influence on FCR for the hole experiment period, except that from 3-4wks which recorded better $(\mathrm{P} \leq 0.05) \mathrm{FCR}$ for the $\mathrm{VC}$-supplem chicks compared with the control ones. On the other hand, the combined interaction effect of $\mathrm{TC} \times \mathrm{VC}$ revealed significant effects during this period from $3-4 \mathrm{wks}$ of age and for the whole experiemental period. The best FCR was recorded for chicks from CT-7 $\times \mathrm{VC}, \mathrm{TC} \times$ control and control $\times \mathrm{VC}$ treatment groups, respectirely (Tabl-5). It is clear from the previous results that both thermal conditioning (TC) of broiler eggs during incubation period and post hatch $\mathrm{VC}$ addition in drinking did not greatly affect feed intake of broiler chicks eccept at specific periode of growther. The influence of $\mathrm{VC}$ in reducing FI was evident during the period from $3-4 \mathrm{wks}$ of age. While the $\mathrm{TC} \times \mathrm{VC}$ interaction showed better FCR for the some period and for the entire experimental time. Our results showed clearly that $\mathrm{VC}$ in drinking water of broiler chicks benifits in reducing total feed intake of broiler chicks during the whole fattening period. This has led to better FCR and consequently an improvement in $\mathrm{TC} \times \mathrm{VC}$-treatment groups. These results are in close agreement with those reported by Mckee and Harrison (1995); Sahin et al. (2003a,b), Kadim et al. (2008); using broiler chicks ; El-Kaiaty et al. (2006).using local strains of chickens and El-Daly et al.(2013)

who used Japanese quail. They concluded that VC improved FCR, perhabs by alleviating the negative effects of heat stress on chicks performance.

Table 4. Effect of thermal conditioning during incubation period on feed intake of broiler chicks

\begin{tabular}{|c|c|c|c|c|c|c|}
\hline $\begin{array}{l}\text { Age (Weak) } \\
\text { Variable }\end{array}$ & 0-1 Wk & 1-2 WK & 2-3 WK & 3-4WK & 4-5 WK & 0-5 WK \\
\hline Thermal Conditioning (TC) & & & & & & \\
\hline Control "C1" & 221.16 & 375.38 & $773.13^{\circ}$ & $974.50^{\mathrm{a}}$ & $628.34^{\circ}$ & $2966.52^{\circ}$ \\
\hline TC-7 & 248.40 & 378.84 & $836.64^{\mathrm{a}}$ & $918.72^{\circ}$ & $715.62^{\mathrm{a}}$ & $3261^{\mathrm{a}}$ \\
\hline TC-14 & 239.44 & 437.40 & $784.00^{\circ}$ & $959.81^{\mathrm{a}}$ & $546.59^{\circ}$ & $2915.77^{\circ}$ \\
\hline SEM & 16.36 & 28.35 & 36.19 & 49.28 & 64.25 & 56.95 \\
\hline Significance & NS & NS & $*$ & $*$ & $*$ & $*$ \\
\hline \multicolumn{7}{|l|}{ Vitamin-C Effect (VC) } \\
\hline 0 & 228.48 & 387.60 & $665.81^{\circ}$ & $852.62^{\circ}$ & $864.32^{\mathrm{a}}$ & $3097.65^{\mathrm{a}}$ \\
\hline $\mathrm{VC}$ & 224.46 & 363.32 & $752.75^{\mathrm{a}}$ & $973.52^{\mathrm{a}}$ & $708.53^{\circ}$ & $2967.55^{\circ}$ \\
\hline SEM & 8.65 & 19.82 & 34.15 & 30.65 & 42.60 & 62.45 \\
\hline Significance & NS & NS & & & $*$ & \\
\hline \multicolumn{7}{|l|}{ TC $\times$ VC Interaction } \\
\hline $\mathrm{C} \times 0$ & 230.16 & 373.92 & 805.35 & 928.26 & 693.64 & 3044.57 \\
\hline $\mathrm{C} \times \mathrm{VC}$ & 218.40 & 382.52 & 782.63 & 1036.80 & 647.46 & 3046.78 \\
\hline $\mathrm{TC} 7 \times 0$ & 246.75 & 367.35 & 916.96 & 772.24 & 799.80 & 2927.32 \\
\hline $\mathrm{TC} 7 \times \mathrm{VC}$ & 244.20 & 384.00 & 807.38 & 1000.45 & 611.68 & 2963.31 \\
\hline $\mathrm{TC} 14 \times 0$ & 208.29 & 443.97 & 848.12 & 841.94 & 803.73 & 3139.87 \\
\hline $\mathrm{TC} 14 \times \mathrm{VC}$ & 239.98 & 383.32 & 752.50 & 1116.92 & 562.32 & 2950.22 \\
\hline SEM & 15.36 & 43.85 & 66.59 & 98.20 & 52.74 & 118.66 \\
\hline Significance & NS & NS & NS & $*$ & * & $*$ \\
\hline
\end{tabular}

a, $b$ and $\mathbf{c}$ Mean within columns with different superscripts are significantly different $(\mathrm{P}<0.05)$. NS $=$ not significant, $*=$ significant at $5 \%$ level, ** = significant at $1.0 \%$ level.

Table 5. Effect of thermal conditioning during incubation period on feed conversion of broiler chicks.

\begin{tabular}{|c|c|c|c|c|c|c|}
\hline $\begin{array}{l}\text { Age (Weak) } \\
\text { Variable }\end{array}$ & 0-1 Wk & 1-2 WK & 2-3 WK & 3-4WK & 4-5 WK & 0-5 WK \\
\hline Thermal Conditioning (TC) & & & & & & \\
\hline Control "C1" & 1.32 & $1.48^{\circ}$ & 1.73 & 1.92 & 2.16 & 1.77 \\
\hline TC-7 & 1.38 & $1.54^{\mathrm{D}}$ & 1.68 & 1.92 & 2.18 & 1.91 \\
\hline TC- 14 & 1.46 & $1.60^{\mathrm{a}}$ & 1.75 & 1.88 & 1.96 & 1.72 \\
\hline SEM & 0.04 & 0.06 & 26.41 & 0.07 & 0.06 & 0.12 \\
\hline Significance & NS & $*$ & NS & NS & NS & NS \\
\hline Vitamin-C Effect (VC) & & & & & & \\
\hline 0 & 1.36 & 1.52 & 1.80 & $1.96^{\mathrm{a}}$ & 2.19 & 1.73 \\
\hline $\mathrm{VC}$ & 1.29 & 1.48 & 1.75 & $1.72^{\circ}$ & 2.10 & 1.66 \\
\hline SEM & 0.08 & 0.05 & 0.03 & 0.07 & 0.09 & 0.11 \\
\hline Significance & NS & NS & NS & $*$ & NS & NS \\
\hline TC $\times$ VC Interaction & & & & & & \\
\hline $\mathrm{C} \times 0$ & 1.37 & 1.52 & 1.77 & 1.95 & 2.12 & 1.82 \\
\hline $\mathrm{C} \times \mathrm{VC}$ & 1.30 & 1.46 & 1.72 & 1.93 & 2.18 & 1.77 \\
\hline TC7 $\times 0$ & 1.41 & 1.55 & 1.76 & 1.96 & 2.25 & 1.74 \\
\hline $\mathrm{TC} 7 \times \mathrm{VC}$ & 1.32 & 1.50 & 1.70 & 1.87 & 2.16 & 1.70 \\
\hline $\mathrm{TC} 14 \times 0$ & 1.31 & 1.58 & 1.82 & 1.94 & 2.19 & 1.84 \\
\hline $\mathrm{TC} 14 \times \mathrm{VC}$ & 1.42 & 1.48 & 1.75 & 1.79 & 2.13 & 1.68 \\
\hline SEM & 0.07 & 0.05 & 0.04 & 0.09 & 0.12 & 0.08 \\
\hline Significance & NS & NS & NS & $*$ & NS & $*$ \\
\hline
\end{tabular}

a, b and c Mean within columns with different superscripts are significantly different $(\mathrm{P}<0.05)$. NS $=$ not significant, * $=$ significant at $5 \%$ level, ** = significant at $1.0 \%$ level. 
Plasma total proteins (TP, Alb, and Globulin):

The effect of TC during incubation and post hatch vitamin $\mathrm{C}$ supplementation to drinking water of hatched chicks, on plasma protein fraction is presended in Table-6. It is clear from the result that plasma TP; albumin, globulin and threir ratio $(\mathrm{A} / \mathrm{G})$ were not significantly influenced by TC of eggs during incubation. However, a significant increase in plasma TP was observed in the VC group of chicks compared with the control ones. On the other hand, the $\mathrm{TC} \times \mathrm{VC}$ interaction effect was not significant.It appears from these results that thermal manipulation of broiler eggs during day 7 or 14 of embryogenic, has failed to exert any effect on plasma protein of hatched chicks at later age (35d). This may be due to the time elapsid between TC during incubation and the age at which blood samples were collected. Since, plasma protein, as a biochemical constituent of blood, are known to be influenced by many other factors including age of the bird, diet, hormones level in blood, and environmental factors. An earlies study by Craig (1985) demonstrated that the main cellular response to heat stress is characterized by a reduction in protein synthesis and turnover. This was also supported by the findings of shourrap (2010) and Badran et al. (2012) who reported that embryonic TC during the periods from 16 to 18 or 14 to17 of incubation did not affect plasma total protein of hatched chicks. On the contrary, Elsayed et al. (2009) who found that TC of local chicken eggs at 39.5 to $40.5^{\circ} \mathrm{C}$ for $3 \mathrm{~h} / \mathrm{d}$ at $15-17$ day of incubation, resulted in a significant increase in plasma total proteins level. Moreover, the significant increase in plasma TP level by vitamin $\mathrm{C}$ addition is in close agreement with many results which showed that the addition of vitamin $\mathrm{C}$ to the drinking water could significantly reduce the physiological stress and hence improve the biochemical parameters of blood (Pardue and Thaxton., 1986);(Kutlu and forbes., 1993a,b);( Konce, et al., 2009);( Imik, et al., 2013) and (Yoo,et al., 2016).

Table 6. Effect of thermal conditioning during incubation period on some blood parameters of broiler chicks.

\begin{tabular}{lcccc}
\hline \multicolumn{1}{c}{ Trait } & $\begin{array}{c}\text { Tp } \\
\text { Treatment }\end{array}$ & $\begin{array}{c}\text { Alb } \\
\text { (g/dl) }\end{array}$ & $\begin{array}{c}\text { Globulin(G) } \\
\text { (g/dl) }\end{array}$ & $\begin{array}{c}\text { A/G } \\
\text { ratio } \\
\text { (g/dl) }\end{array}$ \\
\hline Thermal Conditioning & & & & \\
(TC) & & & & \\
Control "C1" & 4.35 & 2.40 & 1.95 & 1.23 \\
TC-7 & 4.50 & 2.51 & 1.99 & 1.26 \\
TC-14 & 4.54 & 2.51 & 2.03 & 1.24 \\
SEM & 0.12 & 0.07 & 0.05 & 1.4 \\
Significance & NS & NS & NS & NS \\
\hline Vitamin-C Effect(VC) & & & & \\
Control "C" & $4.25^{\circ}$ & 2.39 & 1.86 & 1.28 \\
VC & $4.67^{\mathrm{a}}$ & 2.55 & 2.12 & 1.20 \\
SEM & 0.09 & 0.06 & 0.03 & 2.0 \\
Significance & $*$ & $\mathrm{NS}$ & $\mathrm{NS}$ & $\mathrm{NS}$ \\
\hline TC $\times$ VC Interaction & & & & \\
C1 $\times$ C & 4.17 & 2.39 & 1.78 & 1.34 \\
C1 $\times$ VC & 4.52 & 2.40 & 1.88 & 1.27 \\
TC7 $\times$ C & 4.33 & 2.34 & 1.99 & 1.17 \\
TC7 $\times$ VC & 4.67 & 2.68 & 1.99 & 1.35 \\
TC14 × C & 4.24 & 2.45 & 1.73 & 1.42 \\
TC14 $\times$ VC & 4.83 & 2.57 & 2.26 & 1.14 \\
SEM & 0.16 & 0.10 & 0.06 & 1.66 \\
Significance & NS & NS & NS & NS \\
\hline
\end{tabular}

a, $b$ and $c$ Mean within columns with different superscripts are significantly different $(\mathrm{P}<\mathbf{0 . 0 5})$. NS = not significant, ${ }^{*}=$ significant at $5 \%$ level, $* *=$ significant at $1.0 \%$ level.

\section{REFERENCES}

Abd El-Azim, A (1991). Change in some physiological parameters due to different pre-and post hatch temperatures in poultry. Ph.D. Thesis, Fac. Of Agric., Cairo Univ.

Badran, A.; M. Desoky A, Abou-Eita EM, Stino FK. (2012). Epigenetic thermal adaptation of chickens during late embryonic development. Egypt. Poult. Sci. 32: 675-689.

Bruzual, J.J.;S. D. Peak; J. Brake and E. D. Peebles (2000).Effects of relative humidity during incubation on hatchability and body weight of broiler chicks from young breeder flocks. Poult. Sci., 79:827-830.

El-Daly,E.F.; I. ElWardany; A.H.A.ElGawad;A.E.A. Hemidand N.A.A ElAzeem(2013). Physiological, Biochemical and metabolic responses of Japanese Quail (Coturunix japonica) as affected by early heat stress and dietary treatment. Irani an Journal of Applied Animal Science.3(1):207-216.

El-Kaiaty, A.M.; Faten A.A. Ibrahim; A.M. El-Labban; Azza A. Megahe (2006). Effects of early heat stress on some physiological and Immunological parameters in tow local strains of chickens. J. of Agric. Sci., Mansoura Univ., 31(3): 1329-1343.

Elsayed, N. A. M.; A.E. Alkomy; A.S. Alsaadany and E.Y. Hassan (2009). New suggested schemes for incubation temperature and their effect on embryonic development and hatching power. Asian Journal of Poultry Science., 3:19-29.

Geraert, P. A .; J. C. F. Padiha and S. Guillaumin (1996). Metabolic and endocrine changes induced by chronic heat exposure in broiler chickens : growth performance, body composition and energy retention. Brit. Nutr., 75:195-204.

Imik,H .; O. Kaynar; S. Ozkanlar; R. Gumus; H. Polat and Y. Ozkanlar (2013). Effects of vitamin C and $\alpha$-lipoid acid dietary supplementations on metabolic adaptation of broilers to heat stress . Revue Méd. Vét., 164: 52-59.

Kutlu, H. R. and J. M. Forbes (1993a). Effect of changes in environmental temperature on selfselection of ascorbic acid in colored feeds by broiler chicks. Proc. Nutr. Soc., 52:29A.

Kutlu, H.R. and S.M. Forbes (1993b). Changes in growth and blood parameters in heat stressed broilers chicks in response to dietary ascorbic acid. Livestock Prod. Sci., 36(4): 335-350.

Mashaly,m.m .; G.L. Hendricks ; M.A. Kalama ; A.E. Gehad ;A.O. Abbas and P.H. Patterson (2004) .Effect of heat stress on production parameters and immune responses of commercial laying hens. Poultry Science., 83: 889-894.

May, J. D. and B. D. Lott (1992). Feed and water consumption patterns of broilers at high environmental temperature. Poult. Sci., 76: 627-633.

Mckee, J. M. and P. C. Harrison (1995). Effect of supplemental ascorbic acid on the performance of broiler chickens exposed to multiple concurrent stressors. Poultry Sci., 74: 1772- 1785. 
Pardue, S.L. and J.P. Thaxton, (1986). Ascorbic acid in poultry: a review. World's Poult. Sci. J., 42: 107123.

Sahin, K.; M. Onderci; N. Sahin ; M. F. Gursu and O. Kucuk (2003a). Dietary vitamin c and folic acid supplementation ameliorates the detrimental effects of heat stress in Japanese quail. J. Nutr., 133: 1882- 1886.

Sahin, K.; N. Sahin ;M. Onderci; M. F. Gursu and M.Issi (2003c). vitamin $\mathrm{C}$ and $\mathrm{E}$ can alleviate negative effects of heat stress in Japanese quails. J. of food, Agric. And Envir., 1(2):244-249

Sahin, K.; N. Sahin and O. Kucuk (2003b). Effects of chromium, and ascorbic acid supplementation on growth, carcass traits, serum metabolites, and antioxidant status of broiler chickens reared at a high ambient temperature $\left(32^{\circ} \mathrm{C}\right)$. Nutr Res., 23 : 225-238.

Shourrap, M.I.R (2010). Physiological and cytdogical responces to some environmental factors in poultry. Ph.D.Thesis. Fac. of Agric. Ain shams univ.
Teeter, R.G.; M.O.Smith; F.N.Owers; S.C.Arp; S.Sangia and J.E.Brazil (1985). Chonic heat stress and respiratory alkalosis accurance and treatment in broiler chicks. Poult. Sci., 64: 1060 1064.

Yahav, S. and I. Plavnik (1999). Effect of early-age thermal conditioning and food restriction on performance and thermotolerance of male broiler chickens. Br. Poult. Sci., 40:120-126.

Yalcin, S.and P. Siegel (2003). Exposure to cold or heat during incubation on developmental stability of broiler embryos. Poult. Sci., 82:1388-1392.

Yoo. Jaehong, Young Joo Yi, Bonjin Koo, Samooel Jung, Joung Ung Yoon, Hyun Bae Kang, Do Hun Lee, Jung Min Heo.(2016). Growth performance, intestinal morphology, and meat quality in relation to alpha-lipoic acid associated with vitamin $\mathrm{C}$ and $\mathrm{E}$ in broiler chickens under tropical conditions. R. Bras. Zootec., 45(3):113120.

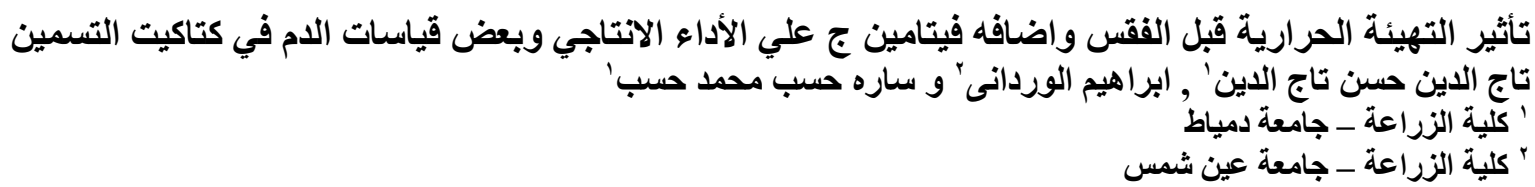

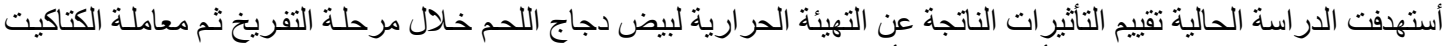

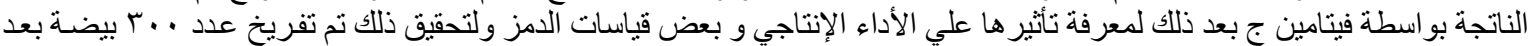

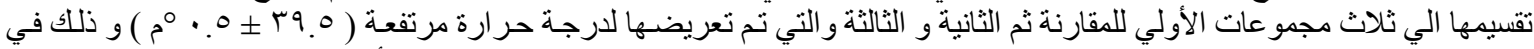

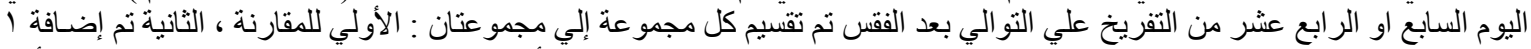

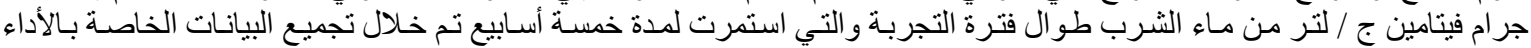

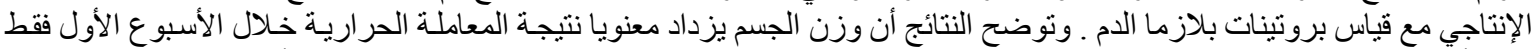

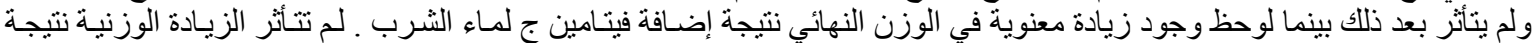

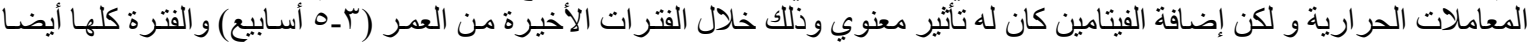

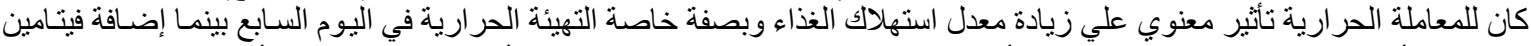

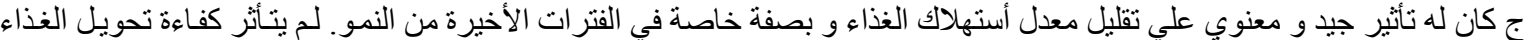

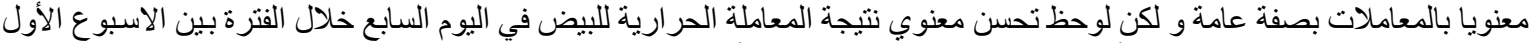

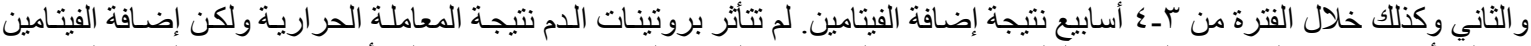

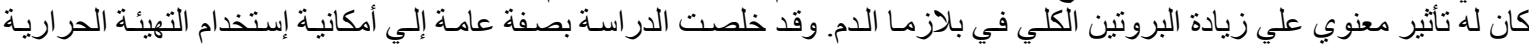

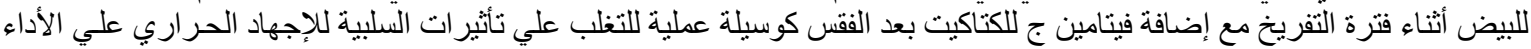

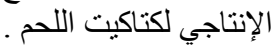

